\title{
Preparation of Hollow Calcium Silicate Microparticles by Simple Emulsion
}

\author{
Eiichi Toorisaka1 ${ }^{*}$, Syotaro Nagamatsu'2, Yasunobu Saruwatari², Makoto Hirata², \\ Tadashi Hano ${ }^{2}$ \\ ${ }^{1}$ Department of Environmental Science and Engineering, Yamaguchi University, Yamaguchi, Japan \\ ${ }^{2}$ Department of Applied Chemistry, Oita University, Oita, Japan \\ Email: torisaka@yamaguchi-u.ac.jp
}

Received 25 September 2014; revised 18 October 2014; accepted 11 November 2014

Copyright (C) 2014 by authors and Scientific Research Publishing Inc.

This work is licensed under the Creative Commons Attribution International License (CC BY). http://creativecommons.org/licenses/by/4.0/

(c) (i) Open Access

\begin{abstract}
Hollow calcium silicate microparticles were prepared by mixing a water-in-oil (W/0) emulsion containing silicate ions in aqueous phase with an oil phase containing a calcium/di-2-ethylhexyl phosphoric acid (D2EHPA) complex. The inorganic precipitation reaction at the oil-water interface was accelerated by using a simple W/0 emulsion. Hollow microparticles were obtained when the mole ratio of D2EHPA and calcium in the oil phase was nearly 2:1. The shell formation of the particles depended on the acceleration of the precipitation reaction, which could be accomplished by controlling the concentrations of the calcium and silicate ions.
\end{abstract}

\section{Keywords}

Hollow Inorganic Microparticle, Water-in-Oil Emulsion, Solvent Extraction, Interfacial Reaction

\section{Introduction}

Hollow microparticles have a huge potential as functional materials, such as the protection of their contents from an outside severe environment, the controlled release of chemicals, and the immobilization of gaseous and liquid materials. Therefore, they have recently been applied in a variety of applications including catalysts, cosmetics, pharmaceuticals and bioreactors [1]-[3]. As a result, their characterization and studies of their practical applications have been extensively conducted. Most of the hollow microparticles are also formed with organic polymers [4] [5], while hollow inorganic microparticles have become of interest because they have a high mechanical strength and thermal stability [5] [6]. To examine these particles and to produce advanced materials with such properties, it is necessary to strictly control their chemical composition, reactivity, and uniformity of morpholo-

${ }^{*}$ Corresponding author.

How to cite this paper: Toorisaka, E., Nagamatsu, S., Saruwatari, Y., Hirata, M. and Hano, T. (2014) Preparation of Hollow Calcium Silicate Microparticles by Simple Emulsion. Journal of Encapsulation and Adsorption Sciences, 4, 114-121. 
gy and particle-size distribution.

We employed a liquid surfactant membrane method [7]-[9], which is a type of interfacial reaction method [10] [11], to prepare inorganic hollow microparticles. This method needs neither special techniques nor special equipment and allows for the preparation of particles by a simple operation. In addition, this method allows the preparation of inorganic hollow particles at room temperature and pressure. Moreover, the capsule size can be controlled over by controlling the size of water droplets in the W/O/emulsion.

In our previous study, a liquid surfactant membrane was used to prepare hollow calcium silicate microparticles, with the following mechanism of preparation [8]. First, the calcium ion and cation carriers react at the interface between the external aqueous and oil phases of the W/O/W emulsions, and a calcium ion-carrier complex is formed. Next, the complex diffuses through the oil phase and reaches the sodium silicate present at the interface between the internal aqueous and oil phases. Thereby, an insoluble calcium silicate shell is formed in the vicinity of the interface by ion exchange between the calcium and sodium ions. During this process, the acceleration of the complex transport to the internal aqueous phase is an important factor for shell formation. However, as described above, the calcium ions must be extracted from the external aqueous phase to the oil phase by the complex formed at the interface. In addition, it was confirmed that the collision of the internal and external aqueous phases of $\mathrm{W} / \mathrm{O} / \mathrm{W}$ emulsions led to the collapse of the internal aqueous phase and the leakage of water to the outer aqueous phase, resulting in the formation of unstructured calcium silicate in the external aqueous phase.

In this study, to overcome this unstable reaction system, an interfacial reaction with simple W/O emulsions was employed for the formation of hollow microparticles. The interfacial reaction was performed by mixing the $\mathrm{W} / \mathrm{O}$ emulsions containing silicate ions in the internal aqueous phase with the oil phase containing the calciumcation carrier complex. In this article, the preparation conditions and morphology of the prepared hollow particles were examined.

\section{Methods}

\subsection{Materials}

Sodium silicate $\left(\mathrm{Na}_{2} \mathrm{O} \cdot 3 \mathrm{SiO}_{2}\right)$, metal chlorides, and kerosene were purchased from Wako Pure Chemical Co., Ltd., Japan. Di-2-ethylhexyl phosphoric acid (D2EHPA) was obtained from Tokyo Chemical Ind. Co., Ltd., Japan. Tetraglycerin condensed ricinoleic acid ester (TGCR) was provided by Sakamoto Yakuhin Co., Ltd., Japan. All chemicals were reagent grade and were used as received.

\subsection{Preparation of Calcium-Loading Solution}

The calcium-loading organic solution was prepared by the liquid-liquid extraction technique. Briefly, $0.5 \mathrm{~mol} / \mathrm{L}$ of aqueous calcium chloride solution $(100 \mathrm{~mL})$ and kerosene $(100 \mathrm{~mL})$ containing $0.5 \mathrm{~mol} / \mathrm{L}$ of D2EHPA as a cation carrier were shaken mechanically in a $500-\mathrm{mL}$ flask for $24 \mathrm{~h}$ at room temperature. The $\mathrm{pH}$ of the aqueous solution was adjusted with $20 \%$ aqueous ammonia. After phase separation, the organic solution containing the calcium ion and D2EHPA complex was employed as a calcium-loading solution for the preparation of the inorganic particles. The calcium distribution ratio $(D)$ was calculated according to Equation (1).

$$
D=[M]_{\text {org }} /[M]_{a q}
$$

$[M]_{a q}$ and $[M]_{o r g}$ are the total equilibrium concentrations of the ions in the aqueous and organic phases, respectively.

\subsection{Preparation of Microparticles with W/O Emulsions}

An aqueous sodium silicate solution $(4.5 \mathrm{~mL})$ and a kerosene solution $(40.5 \mathrm{~mL})$ containing TGCR as a surfactant were mixed using a homogenizer (MA-2500, Tokushukika Co., Ltd., Japan) at $2500 \mathrm{rpm}$ for 10 min to produce the $\mathrm{W} / \mathrm{O}$ emulsions. The obtained emulsions $(10 \mathrm{~mL}$ ) were poured into the calcium-loading solution (100 $\mathrm{mL}$ ) and stirred at $50 \mathrm{rpm}$. The solid products formed in the emulsions were filtered off, washed with distilled water, and dried. The preparation was performed at room temperature.

The interfacial reaction with $\mathrm{W} / \mathrm{O} / \mathrm{W}$ emulsions as control was performed as mentioned in previous paper [8]. 


\subsection{Analysis}

Surface and cross-sectional views of the microparticles were obtained with a scanning electron microscope (SEM, JEOL, JSM-6060). The cross-section samples were prepared by sectioning the epoxy resin embedding the micropartilces. The aqueous metal-cation concentrations were measured using inductively coupled plasma spectrometry (ICP, Shimadzu, ICPS-7000). The concentration of the metal-cation in the organic solution was treated by a back-extraction into $1.0 \mathrm{~mol} / \mathrm{L}$ of hydrochloric acid and then measured.

\section{Results and Discussion}

\subsection{Preparation of Hollow Particles Using Metal-Loading Solution}

Figure 1 shows the formation mechanism of calcium silicate particles in W/O emulsions. The transport of calcium ions in this process becomes simpler than that in $\mathrm{W} / \mathrm{O} / \mathrm{W}$ emulsions. The complex of calcium ion and ioncarrier D2EHPA in the oil phase was formed by the solvent-extraction process, described above. Figure 2 shows the effect of the $\mathrm{pH}$ value of aqueous solution on the extraction behavior of the calcium ions. The extracted amount of the calcium ion into the oil phase depended on the $\mathrm{pH}$ value of aqueous solution; As the $\mathrm{pH}$ increases, the extraction ratio also increases. When the solution $\mathrm{pH}$ was above 6 , the calcium-distribution ratio was almost equal. The formation of the calcium-D2EHPA complex proceeds by the ion exchange of calcium ion with the hydrogen ion of D2EHP; The calcium ion is extracted into the oil phase. The calcium ion and D2EHPA then combine in a 1:2 ratio. Thereby, it is found that above $\mathrm{pH}$ 6, the distribution ratio of calcium ions is approximately 1, and almost all the D2EHPA forms complexes with calcium.

The preparation of hollow particles using the W/O emulsion was investigated by using the calcium-loading oil solution prepared by the above-mentioned pretreatment (Figure 3). When almost all of D2EHPA in the oil phase combines with calcium (calcium-loading ratio is $96 \%$ ), the particles prepared using the oil phase formed a hollow structure. In contrast, the particles were not hollow when the solution containing a $60 \%$ calcium-loading ratio was used. Each of the prepared particles displayed a spherical structure reflecting the water droplets of the emulsions. The concentration of calcium ion in the oil phases in the different emulsions is also almost equal. From this result, it was assumed that the substitution degree of calcium in D2EHPA affects the shell formation of the hollow particles. Therefore, the interfacial reaction was attempted using the D2EHPA solution as the oil phase instead of a calcium-loaded solution. The products obtained were filled, spherical particles. This result shows that $\mathrm{H}^{+}$released from D2EHPA and silicate caused the inorganic precipitation reaction. It is known from our previous experiment that the formation of a hollow structure is difficult in the case of the interfacial reaction between $\mathrm{H}^{+}$and silicate. It is believed that when a $60 \%$ calcium-loading solution was used for the interfacial reaction, the $\mathrm{H}^{+}$ions contained in the $40 \%$ D2EHPA were used to fill the inner space. Accordingly, it is important to employ D2EHPA predominantly bound to calcium instead of $\mathrm{H}^{+}$to form hollow calcium silicate particles by this reaction.

\subsection{Reaction Rate of Interfacial Reaction Using W/0 Emulsions}

It was observed that the shell of the microcapsules is formed by a rapid inorganic precipitation reaction at the

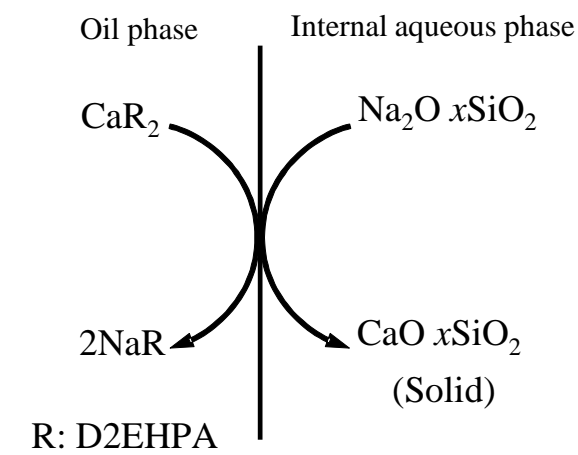

Figure 1. Formation mechanism of calcium silicate hollow particles. 


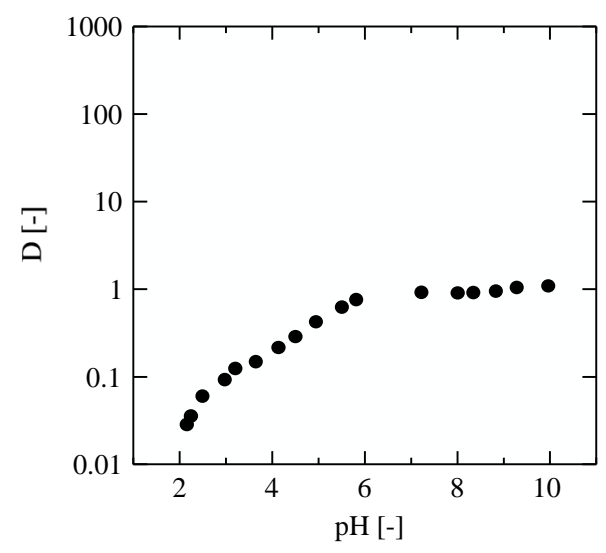

Figure 2. Effect of equilibrium $\mathrm{pH}$ on the distribution ratio of calcium ion.
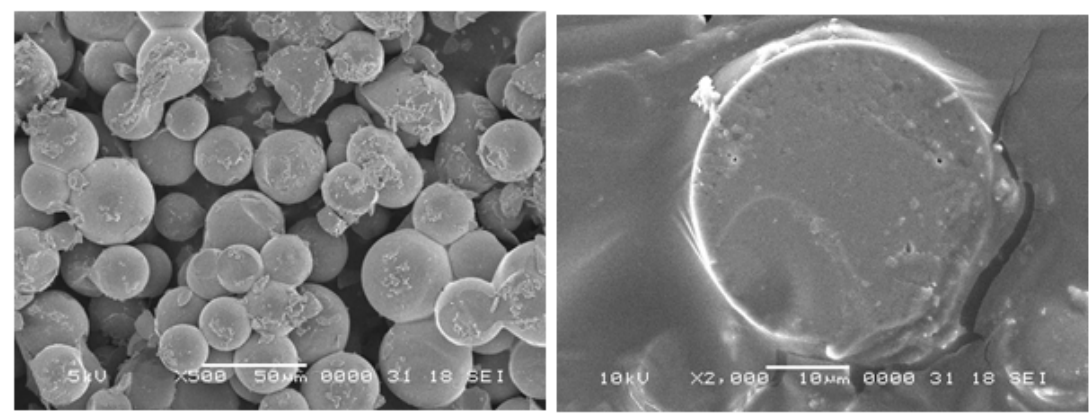

(a)
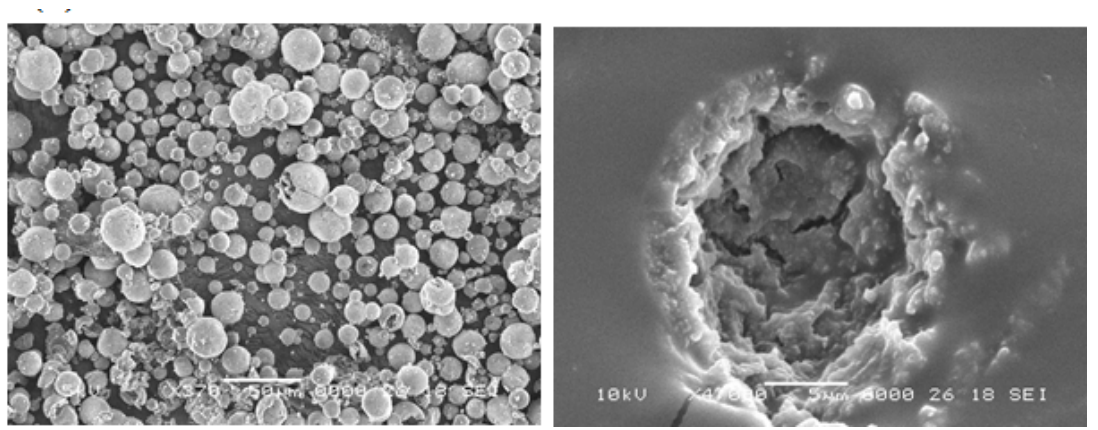

(b)

Figure 3. SEM photographs of surface and cross section of microparticles formed from different Ca loading ratios. Ion-exchange ratios of D2EHPA were (a) $60 \%$ and (b) $96 \%$. Photographs on the left and right sides show the surface and cross section of the particles, respectively.

interface between the internal aqueous and oil phases. Control of the calcium-ion transport, which directly affects the reaction rate, is important to form the hollow structure. In the case where $\mathrm{W} / \mathrm{O} / \mathrm{W}$ emulsions were used for the reaction, calcium ions are transported from the outer aqueous phase to the inner aqueous phase. The transport rate is controlled by the complex-formation process between the calcium ions in the outer aqueous phase and D2EHPA as a metal-cation carrier in the oil phase, as well as the diffusion of the complex through the oil phase. Thus, it was found that the higher the D2EHPA concentration, the higher the rate of calcium-cation transport. In this study, W/O emulsions were employed to simplify the calcium-ion transport process. Figure 4 shows the changes in the metal-cation concentrations in the outer aqueous phase of the $\mathrm{W} / \mathrm{O} / \mathrm{W}$ emulsions and the oil phase of the $\mathrm{W} / \mathrm{O}$ emulsions over time. The decrease in the calcium concentration and the increase in the 


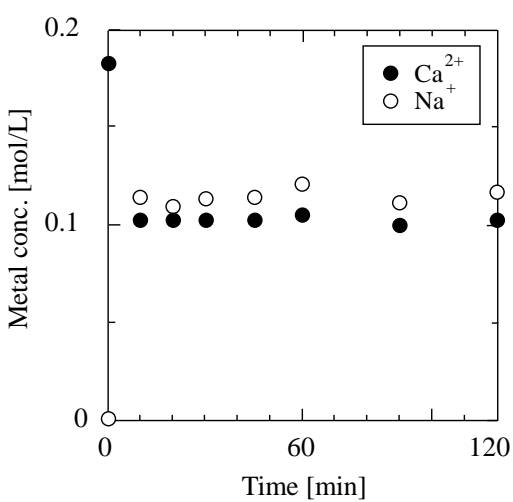

(a)

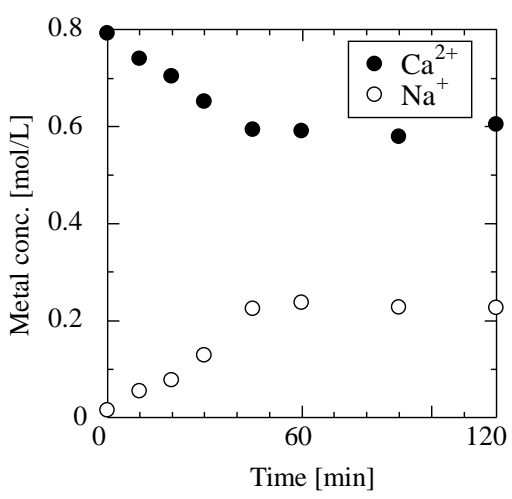

(b)

Figure 4. Metal concentration in the (a) oil phase of W/O emulsion and (b) external aqueous phase of $\mathrm{W} / \mathrm{O} / \mathrm{W}$ emulsion as a function of time.

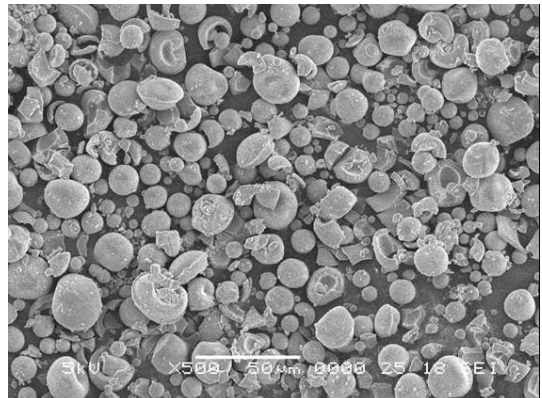

(a)
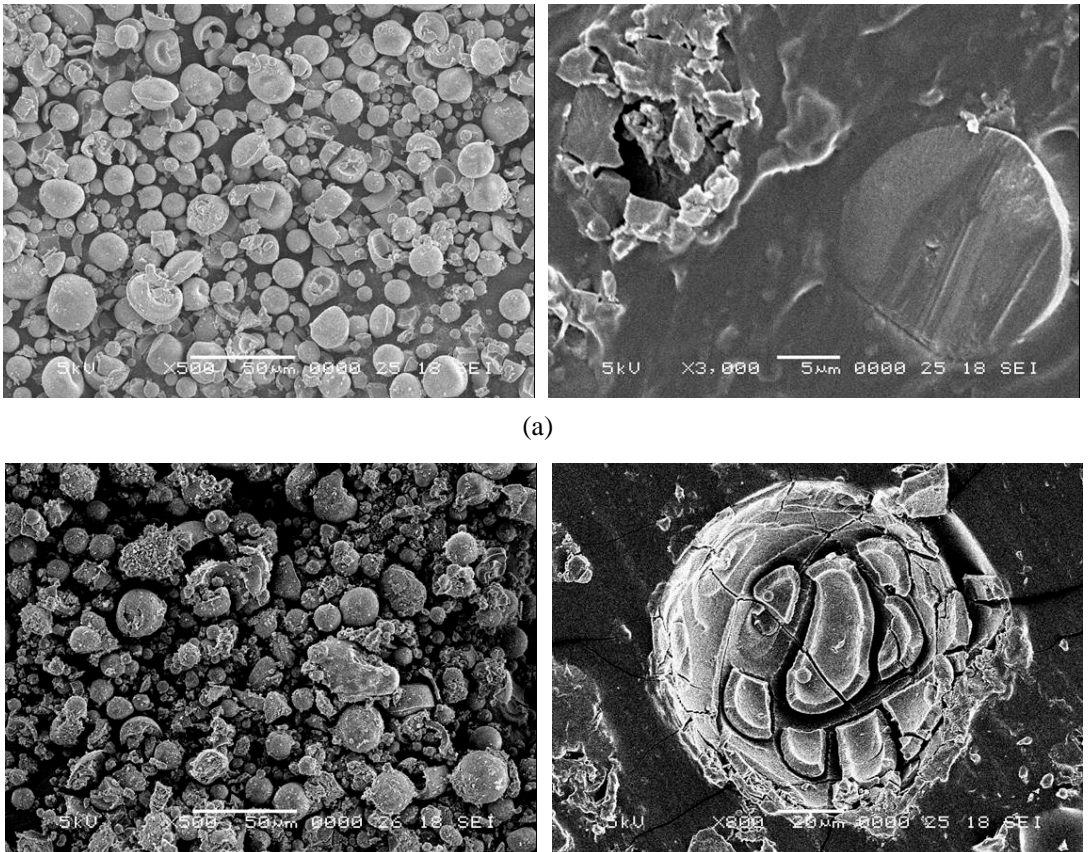

(b)
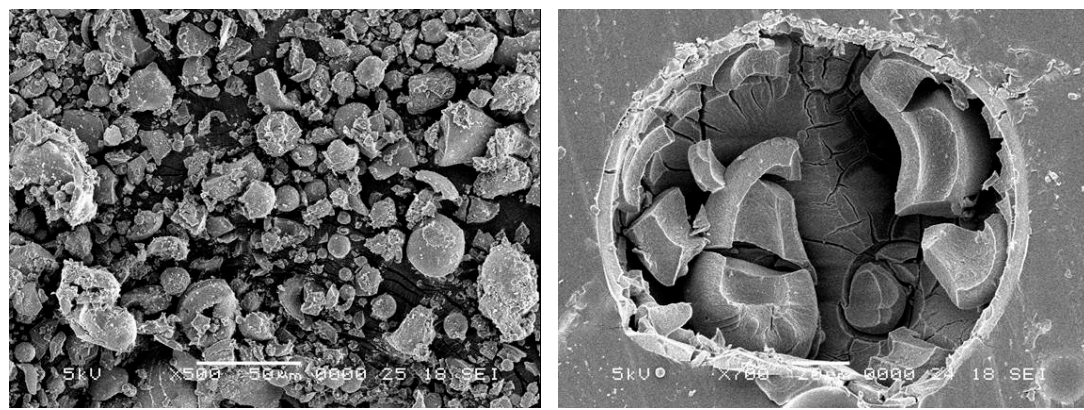

(c)

Figure 5. SEM photographs of the surface and cross section of microparticles formed from different calcium concentrations in the oil phase. Concentrations of calcium ion in the loading solution were (a) $0.036 \mathrm{M}$, (b) $0.072 \mathrm{M}$, and (c) $0.24 \mathrm{M}$. Photographs on the left and right sides show the surface and cross section of the particles, respectively. 
sodium concentration indicate the progress of the precipitation and ion-exchange reactions. When the amount of metal transported is a constant, the reaction is complete. As shown in Figure 4, the W/O emulsions promote the reaction more than the W/O/W emulsions do. For the W/O emulsions, nearly all of the D2EHPA in the oil phase forms a complex with calcium ions, and the calcium ions are transported from the oil phase to the inner aqueous phase. Thus, it is believed that the W/O emulsions are advantageous for forming the calcium silicate shell.

\subsection{Effect of Concentration of Silicate and Calcium Ions on the Formation of Hollow Shell}

Hollow calcium silicate particles are formed by the precipitation reaction between calcium and silicate ions in the vicinity of the interface between the inner aqueous phase and the oil phase. It is believed that the concentration of each ion affects the formation of the particle's shell. Figure 5 shows the effect of the calcium-ion concentration on the formation of the hollow particles using the W/O emulsions. Though hollow particles were partially obtained when the oil phase containing $0.036 \mathrm{~mol} / \mathrm{L}$ calcium ion was used, most of them were filled (Figure 5(a)). It was also confirmed that as the concentration of the calcium ion increases, the number of particles with a hollow structure, as well as the formation of non-spherical particles, increases (Figure 5(b), Figure 5(c)). In a previous investigation, it was found that D2EHPA destroys the emulsions stabilized by surfactants. Increases in the concentration of D2EHPA must be accompanied as an increase in the amount of calcium ions in the oil phase. Thus, it is believed that when the calcium-ion concentration is increased, the preparation of spherical particles becomes difficult.

Figure 6 show the effect of the silicate-ion concentration on the formation of the hollow particles. The oil
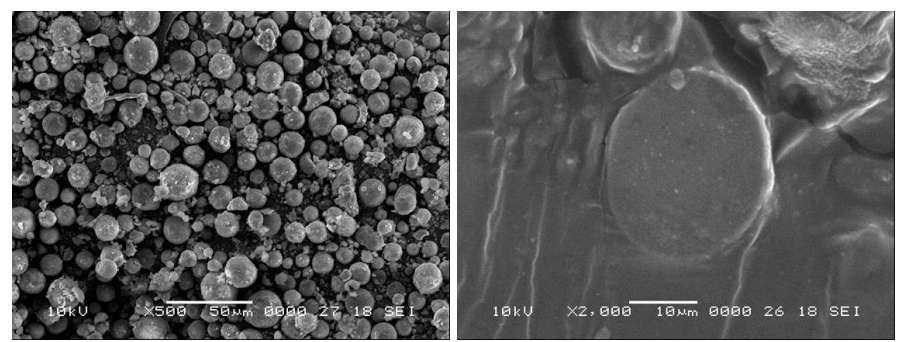

(a)
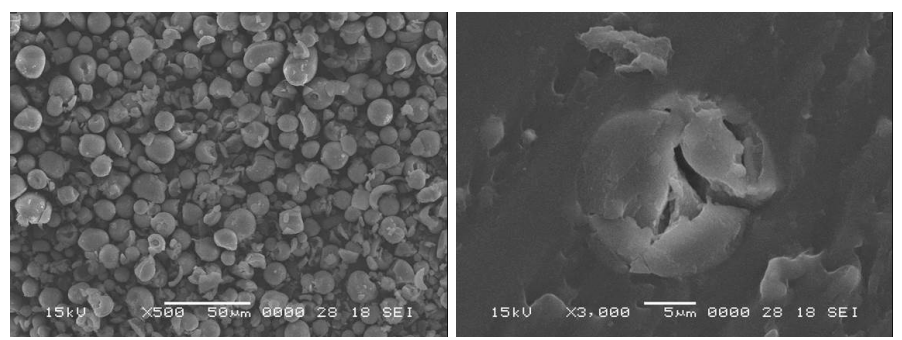

(b)
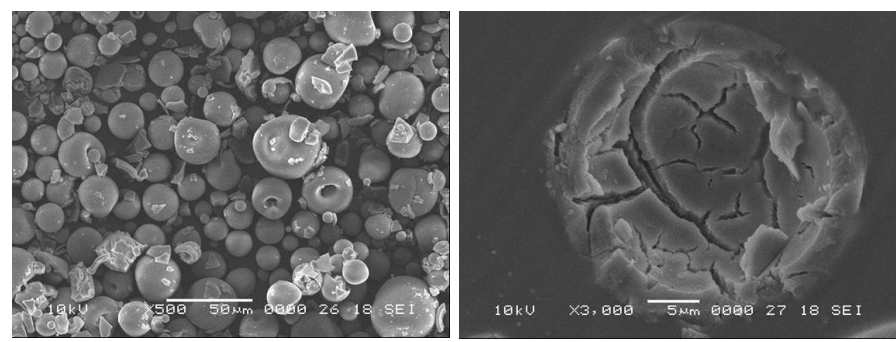

(c)

Figure 6. SEM photographs of the surface and cross section of microparticles formed from different silicate concentrations in the internal aqueous phase. Silicate concentrations were (a) $0.5 \mathrm{M}$, (b) $1.0 \mathrm{M}$, and (c) $1.5 \mathrm{M}$. Photographs on the left and right sides show the surface and cross section of the particles, respectively. 


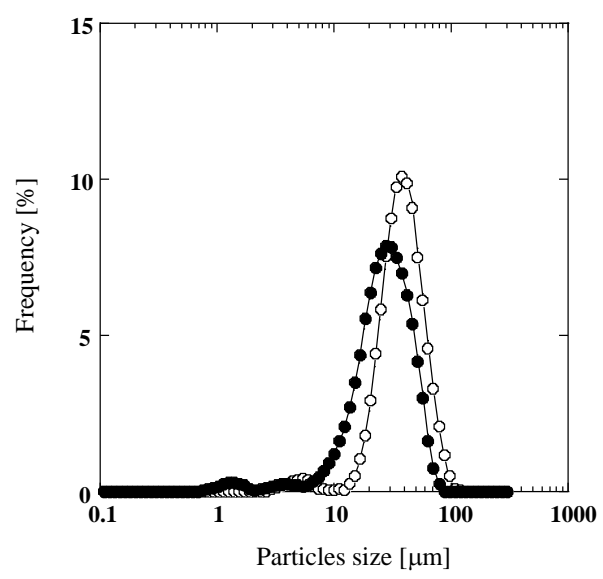

Figure 7. Particle size distributions of hollow particles formed used $(\bullet) \mathrm{W} / \mathrm{O}$ emulsions and (०) $\mathrm{W} / \mathrm{O} / \mathrm{W}$ emulsions

phase containing $0.036 \mathrm{~mol} / \mathrm{L}$ calcium ion was used as the source of metal ions. When the concentration of the silicate ion was not high enough, the products were filled particles (Figure 6(a)). The higher the concentration of silicate ion, the larger the hollow space in the particles (Figure 6(b), Figure 6(c)). It is believed that the increase in the silicate-ion concentration promotes a rapid precipitation in the vicinity of the interface, thus promoting the shell formation.

Moreover, the size distribution of the hollow particles showed in Figure 6(c) and the particle prepared using $\mathrm{W} / \mathrm{O} / \mathrm{W}$ emulsion with same concentration of silicate ion was almost similar (Figure 7). It was confirmed that simple W/O emulsion allows promote the interfacial reaction and form spherical hollow microparticles by a simple process.

\section{Conclusion}

Hollow calcium silicate particles were prepared by an inorganic precipitation reaction at the oil-water interface in W/O emulsions. The loading of calcium ion into the oil phase allows the transport of calcium ion into the inner aqueous phase and accelerates the reaction. Controlling the concentrations of calcium ion in the oil phase and silicate ion in the aqueous phase was also important for forming hollow particles. The preparation method of inorganic hollow particles shown in this article is a simple process, and its application to the preparation of the other hollow particles is promising.

\section{References}

[1] Caruso, F. (2000) Hollow Capsule Processing through Colloidal Templating and Self-Assembly. Chemistry —A European Journal, 6, 413-419. http://dx.doi.org/10.1002/(SICI)1521-3765(20000204)6:3<413::AID-CHEM413>3.0.CO;2-9

[2] Sarti, S. and Bordi, F. (2013) Polymeric Hollow Micro and Nanospheres for Biotechnological Applications: A focused Review. Materials Letters, 10, 134-139. http://dx.doi.org/10.1016/j.matlet.2013.07.003

[3] Brun-Graeppi, A.K.A.S., Richard, C., Bessodes, M., Scherman, D. and Merten, O.W. (2011) Cell Microcarriers and Microcapsules of Stimuli-Responsive Polymers. Journal of Controlled Release, 149, 209-224. http://dx.doi.org/10.1016/j.jconrel.2010.09.023

[4] Lensen, D., Vriezema, D.M. and van Hest, C.M. (2008) Polymeric Microcapsules for Synthetic Applications. Macromolecular Bioscience, 8, 991-1005. http://dx.doi.org/10.1002/mabi.200800112

[5] Hu, J., Chen, M., Fang, X. and Wu, L. (2011) Fabrication and Application of Inorganic Hollow Spheres. Chemical Society Reviews, 40, 5471-5491. http://dx.doi.org/10.1039/c1cs15103g

[6] Bertling, J., Blömer, J. and Kümmel, R. (2004) Hollow Microsphere. Chemical Engineering \& Technology, 27, 829837. http://dx.doi.org/10.1002/ceat.200406138

[7] Morishige, I., Hirata, M., Toorisaka, E., Ohtakem, T. and Hano, T. (2005) Preparation of Various Metal-Silicate Microballoons Using W/O/W Emulsion. Journal of Microencapsulation, 22, 291-301. 
http://dx.doi.org/10.1080/02652040500100527

[8] Toorisaka, E., Morishige, I., Hirata, M. and Hano, T. (2010) Effect of Preparation Conditions on Calcium-Silicate Microcapsule Formation Using a Liquid Surfactant Membrane. ITE-IBA Letters on Batteries, New Technology \& Medicine, 3, 36-40.

[9] Toorisaka, E., Morishige, I., Hirata M. and Hano, T. (2010) Preparation of Multiple Metal-Silicate Microcapsules with Emulsified Liquid Membrane. ITE-IBA Letters on Batteries, New Technology \& Medicine, 3, 46-52.

[10] Fujiwara, M., Shiokawa, K., Tanaka, Y. and Nakahara, Y. (2004) Preparation and Formation Mechanism of Silica Microcapsules (Hollow Sphere) by Water/Oil/Water Interfacial Reaction. Chemistry of Materials, 16, 5420-5426. http://dx.doi.org/10.1021/cm048804r

[11] Fujiwara, M., Shiokawa, K., Sakakura, I. and Nakahara, Y. (2010) Preparation of Hierarchical Architectures of Silica Particles with Hollow Structure and Nanoparticles Shells: A Material for the High Reflectivity of UV and Visible Light. Langmuir, 26, 6561-6567. http://dx.doi.org/10.1021/la9043396 
Scientific Research Publishing (SCIRP) is one of the largest Open Access journal publishers. It is currently publishing more than 200 open access, online, peer-reviewed journals covering a wide range of academic disciplines. SCIRP serves the worldwide academic communities and contributes to the progress and application of science with its publication.

Other selected journals from SCIRP are listed as below. Submit your manuscript to us via either submit@scirp.org or Online Submission Portal.
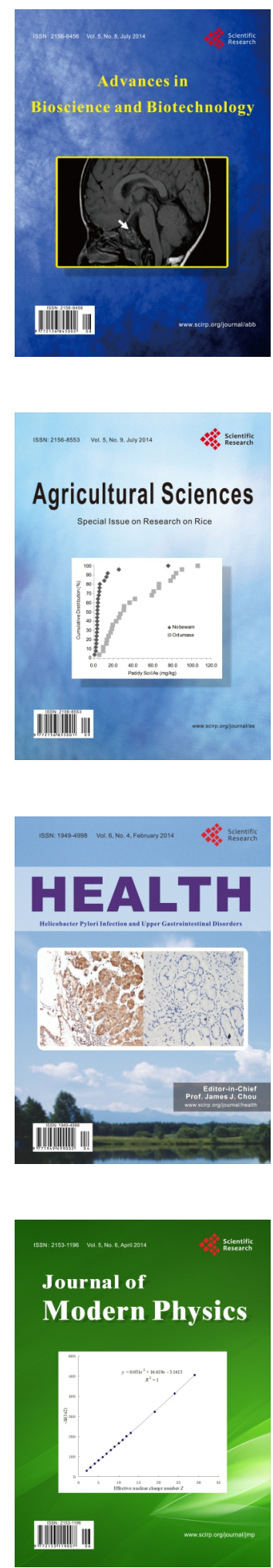
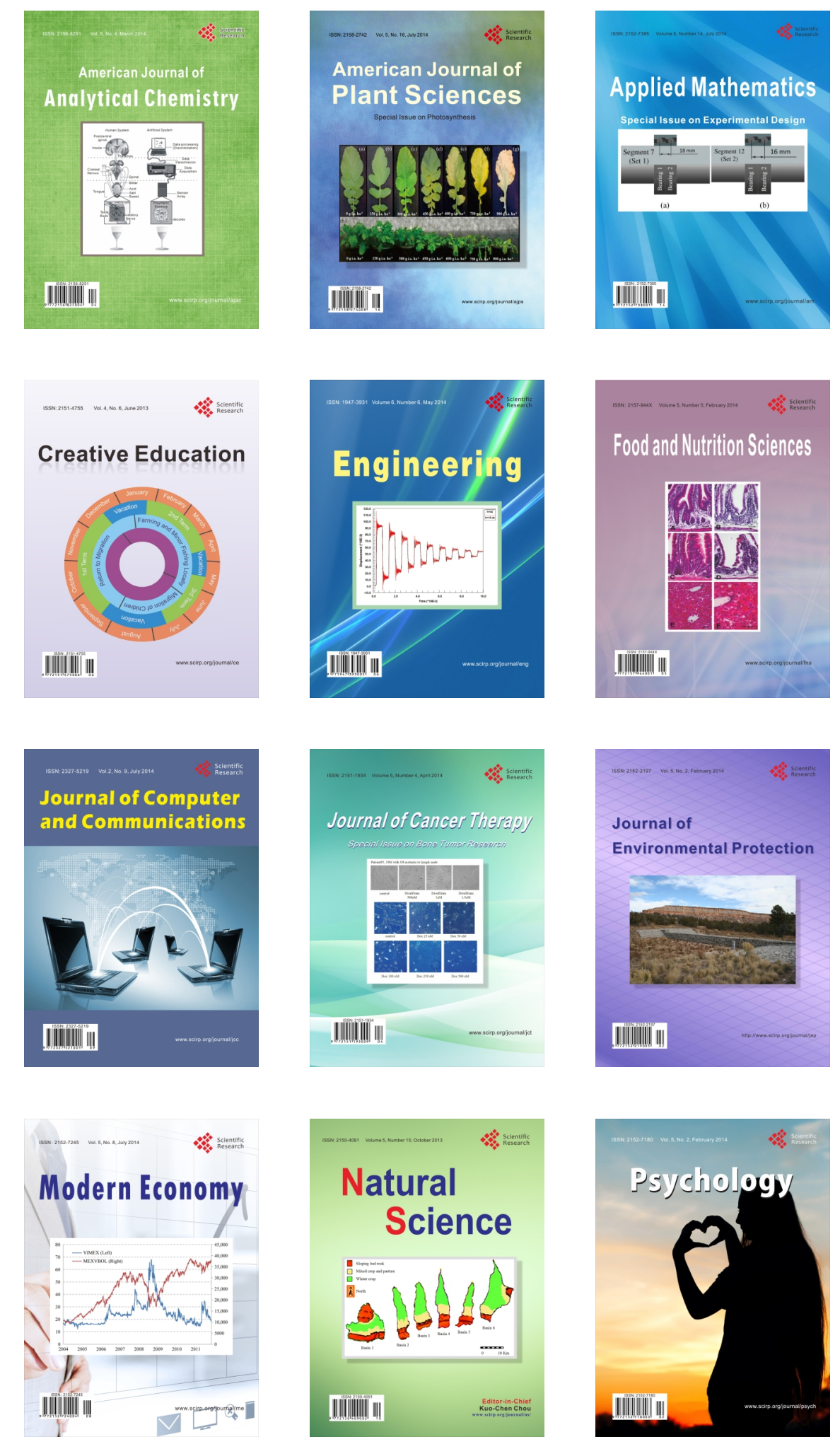